JINOTEP Vol 8 (3) (2021): 266-276

DOI: $10.17977 /$ um031v8i32021p266

JINOTEP (Jurnal Inovasi Teknologi Pembelajaran

Kajian dan Riset Dalam Teknologi Pembelajaran

http://journal2.um.ac.id/index.php/jinotep/index

\title{
PERANCANGAN ARCA 3D SEBAGAI KARAKTER AUGMENTED REALITY (AR) DALAM MENINGKATKAN MINAT SEJARAH MASYARAKAT
}

\author{
Dio Fajar Pirmansyah, Andy Pramono \\ Jurusan Pendidikan Seni dan Desain, Fakultas Sastra, Universitas Negeri Malang
}

\begin{tabular}{l} 
Article History \\
\hline Received:16-07-2021 \\
Accepted: 20-09-2021 \\
Published: 01-11-2021 \\
Keywords \\
\hline
\end{tabular}

Augmented reality;

Arca 3D; Modeling

\begin{abstract}
Abs trak
Desain arca 3D sebagai augmented reality di inovasikan sebagai media pengenalan arca daerah kabupaten Tulungagung. Banyak arca yang ditemukan di daerah Tulungagung namun masyarakat sekitar belum bisa tahu tentang arca yang ada di Tulungagung sehingga dengan tujuan adanya augmented reality masyarakat dapat mengetahui darimedia sosial dan dengan teknologi yang dapat memunculkan 3D arca. Dari hasil penelitian menjelaskan bahwa survei yang telah dilakukan sebagian besar kuisioner menyatakan bahwa model dan informasi telah sesuai sebagaimana dari arca aslinya.berdasarkan dari survei kesesuaian dan akurasi model dan visual ar didapatkan keakurasian sebesar $89 \%$ serta pada survei aplikasi ar arca informatif dan pengenalan sejarah didapatkan nilai sebesar 83\% dari kurang lebih 60 kuesioner dapat disimpulkan bahwa augmented reality merupakan media yang cocok untuk mengenalkan situs sejarah dan memberi edukasi kepada masyarakat.

Abstract

The design of $3 D$ statues as AR was innovated as a medium for introducing regional statues in Tulungagung Regency. Many statues are found in the Tulungagung area but the surrounding community cannot yet know about the statues in Tulungagung so that with augmented reality people can find out from social media and with technology that can bring up 3D statues From the results of the study, it was explained that the survei that had been carried out, most of the questionnaires stated that the model and information were in accordance with the original statue. obtained a value of $83 \%$ from approximately 60 questionnaires. It can be concluded that the augmented reality is a suitable medium to introduce historical sites and provide education to the public.
\end{abstract}

Corresponding author:

Andy Pramono

Address:Jl. Semarang No.5, Sumbersari, Kec. Lowokwaru,

Kota Malang, Jawa Timur 65145

E-mail: andy.pramono.fs@um.ac.id

2021 Universitas Negeri Malang p-ISSN 2406-8780 e-ISSN 2654-7953 


\section{PENDAHULUAN}

Kabupaten Tulungagung salah satu kabupaten yang terletak di Provinsi Jawa Timur. Daerah tersebut dikenal sebagai penghasil marmer terbesar di Indonesia dan memiliki banyak situs sejarah dengan motif Hindu dan Budha, salah satunya berupa candi. Dalam sejarah daerah, terdapat banyak kepercayaan agama Hindu dan Budha di situs sejarah dan peninggalan di kabupaten Tulungagung. Karena letaknya yang strategis dan daerah perkembangan dari Kerajaan Kediri hingga Kerajaan Majapahit. Museum wajakensis sebagai salah satu sumber belajar di kabupaten Tulungagung merupakan tempat penyimpanan benda-benda bersejarah. Setiap daerah biasanya memiliki museum sebagai koleksi benda-benda bersejarah (Untari, 2018). Arca merupakan patung yang dibuat dengan tujuan utama sebagai media keagamaan, yaitu sarana dalam memuja tuhan bagi umat hindu dan budha (Rahmawati, 2017).

Arca merupakan peninggalan sejarah yang memiliki sisi magis dan spiritual yang tinggi oleh sebab itu arca berbeda dengan patung bias, dan dengan adanya kemajuan di bidang teknologi dan pendidikan saat ini, merupakan salah satu upaya dalam menunjang kegiatan belajar mengajar dengan menggunakan sarana teknologi Augmented reality (AR) (Kasih, 2014), yang merupakan hasil seni yang dimaksudkan sebagai sebuah keindahan. Menurut lee, augmented reality sangat berpotensi dalam menarik, menginspirasi, dan memotivasi pelajar, untuk mengeksplorasi dan melakukan pengontrolan dari berbagai perspektif yang berbeda, yang sebelumnya tidak menjadi bahan pertimbangan dalam dunia pendidikan. Kaufmann (2002) menjelaskan dari institute of software technology and interactive systems vienna university of technology austria mendukung hal tersebut dalam papernya yang berjudul "collaborative augmented reality in education".

Hal tersebut sependapat dengan pendapat dari Cravens (2001) yang menjelaskan bahwa diferensiasi dalam pemasaran akan menghasilkan promosi yang unggul karena berbeda dengan pesaingnya.dengan dibuatnya filter di media sosial nantinya arca yang terdapat di museum wajakensis akan lebih dikenal masyarakat luas dengan seiring banyak digunakannya filter tersebut dalam sosial media. Beberapa penelitian menjadi landasan dalam pada penelitian ini. Penelitian (Pramono, 2020) terkait aplikasi augmented reality untuk topeng malang juga menjadi implementasi desain dalam arca. Desain arca 3D nantinya digunakan dalam bentuk filter di berbagai media social. Penelitian Eriza terkait pemodelan objek 3D untuk implementasi aplikasi AR (Eriza dkk., 2021). Novica dkk, (2020) menjelaskan terkait desain model 3D untuk maskot kota malang dan aset topeng malang pada permainan juga menjadi acuan penelitian ini.

\section{METODE}

Penerapan teknologi informasi (TI) dalam proses transmisi informasi telah berkembang pesat. Saat ini, teknologi terkini yang digunakan untuk transmisi informasi adalah teknologi augmented reality (AR). Dalam teknologi AR, pengguna dapat memvisualisasikan objek atau benda bersejarah dalam 3 dimensi. AR memiliki keunggulan interaktivitas dan real-time, sehingga AR sebagai media untuk memperkenalkan benda-benda bersejarah sebagai warisan budaya telah banyak digunakan dalam bidang pendidikan. Sebagai cagar budaya, peninggalan sejarah termasuk dalam kategori cagar budaya. Benda cagar budaya memiliki arti khusus bagi sejarah, ilmu pengetahuan, pendidikan, agama dan budaya. Selain itu, benda cagar budaya juga memiliki nilai budaya yang meningkatkan individualisme bangsa.

Mengingat pentingnya keberadaan cagar budaya, maka informasi tentang keberadaan benda cagar budaya harus diketahui masyarakat. Serta perancangan filter arca 3D ini terdapat 3 tahapan produksi yaitu mulai dari pra-produksi, produksi, dan yang terakhir pasca produksi. Tahap pra produksi merupakan tahap awal dalam setiap proses pembuatan filter arca 3D ini. Bagian-bagian dalam pra produksi antara lain penetapan ide, melakukan riset data dan fakta, penuangan ide dalam bentuk naskah dan pembuatan storyboard (Rosyidah, 2012).

\section{Tahap Model Pe rancangan}

Dalam tahap ini penulis mengumpulkan data-data berupa informasi umum mengenai Arca yang ada di daerah kabupaten Tulungagung dan nantinya akan menjadi model 3D sebagai Augmented reality. Penulis juga mengambil referensi di internet mengenai arca yang ada di daerah lain karena dalam museum bentuk arca tidak utuh. Pada Perancangan Arca 3D Sebagai AR (Augmented reality) Dalam Meningkatkan Minat Masyarakat Daerah Tulungagung Mengenal Situs Sejarah adalah proses produksi, pada tahap ini semua bahan yang sudah dibuat 


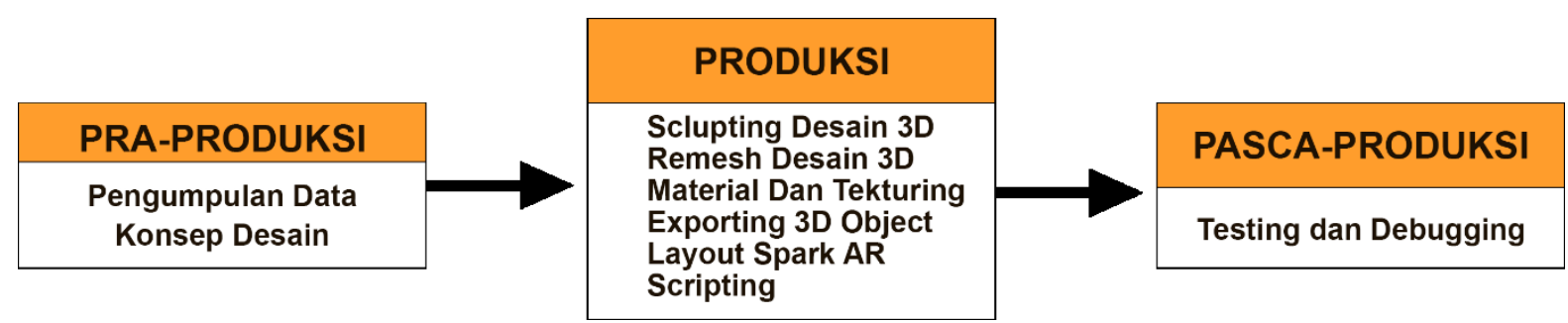

\section{Gambar 1. Bagan Alur Pe rancangan}

di pra-produksi diolah dengan software Blender 3D, Substance painter, Zbrush dan Spark AR. Hal yang meliputi proses produksi ini adalah sculpting, remeshing, material dan texturing, layouting, dan Export.

\section{Tahap Testing dan Debugging}

Tahap produksi sudah selesai maka tahap selanjutnya adalah menguji coba aplikasi yang telah dibuat. Pada tahap ini sangat disarankan untuk bisa sedetail mungkin dalam memperhatikan berbagai bagian, terutama jika ditemukan adanya bug ataupun error yang akan dilanjutkan pada tahap debugging. debugging merupakan metode yang digunakan oleh programmer untuk menemukan dan menyelesaikan error pada program atau aplikasi komputer agar dapat bekerja sesuai dengan yang diharapkan. Proses ini membutuhkan ketelitian dan pemahaman tentang software Spark AR yang digunakan, karena pesan error yang muncul menandakan bahwa filter Instagram tidak dapat dijalankan. Kesalahan tersebut dapat disebabkan oleh beberapa bagian seperti salah ketik, bagian tidak disertakan atau bagian sisa. Hal-hal yang disebabkan. Selama pembuatan skrip, dan lainnya.

\section{HASIL}

Perancangan desain arca 3D mencakup beberapa bagian yang mendukung kelengkapan dari filter augmented reality. Adapun bagianbagian tersebut secara rinci dijelaskan sebagai berikut :

\section{Tahap Konsep Desain}

Konsep Desain merupakan dasar pemikiran desainer untuk membuat suatu bentuk desain. Dan dalam usahanya memecahkan tuntutan desain (Dewanto, 2011). Referensi model arca ini diperoleh di kabupaten museum daerah Tulungagung dan media internet. Acara yang dipilih meliputi Arca jaladwara, Arca Nandi, Arca Dwaparla, Arca Ganesha dan Arca dhyani. penulis memilih arca tersebut karena bentuknya mewakili daerah Tulungagung dan memiliki filosofi tertentu pada arca tersebut. dari arca arca tersebut akan dibuat sebuah model 3D dengan software zbrush, blender. dan nantinya akan diterapkan menjadi ar dengan menggunakan software Spark AR.

Dari referensi model arca yang ada di daerah kabupaten Tulungagung. diperoleh hasil berupa 5 bentuk arca dapat dilihat pada Gambar Diagram alir

Pengertian diagram alir flowchart adalah suatu kaidah menjelaskan tentang solusi bagian yang menampilkan simbol-simbol terbatas yang mudah dimengerti, mudah digunakan (Sari, dkk. 2013), dari perancangan diagram alir ini diperoleh hasil berupa 5 tampilan yang akan didesain pada spark ar. Alur dari diagram alir dapat dilihat pada Gambar 4.

\section{Tahap Produksi \\ Sculpting}

Proses membuat model dengan cara memberikan brush pada clay atau objek sphere yang ada pada software. Pada tahap sculpting menjadi 2 bagian dari base mesh dan selanjutnya detail pada bagian 3D model. Dalam pembuatan arca menggunakan software zbrush dan blender.

\section{Remesh Model}

3D pada tahap ini penulis membuat model 3D arca dengan high poly menjadi low poly model,dengan cara meretopo objek sculpting dengan tools yang ada pada software zbrush maupun blender. hal ini dilakukan supaya model 3D menjadi ringan dan bisa dimasukan di software spark AR.

\section{Material dan Texturing}

Material and Texturing adalah sistem untuk memberikan tekstur dan properti material ke objek model yang telah dibuat. Proses material dan tekstur memainkan peran penting dalam membuat objek 3D terlihat nyata (Aditya, 2007). Material dalam perangkat lunak 3D adalah unsur yang mendefinisikan substansi 


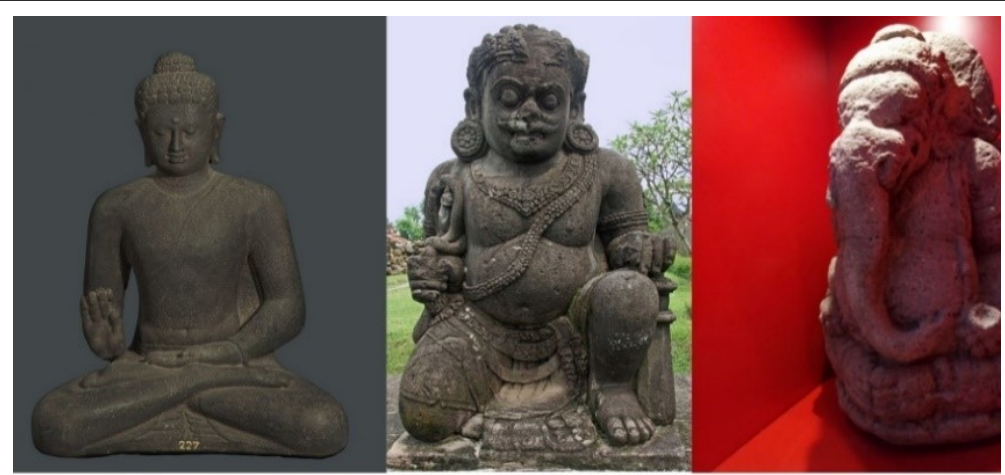

ARCA BUDHAYANI ARCA DWAPARLA ARCA GANESHA

Gambar 2. Gambar Arca Sumber gambar: dokumen pribadi

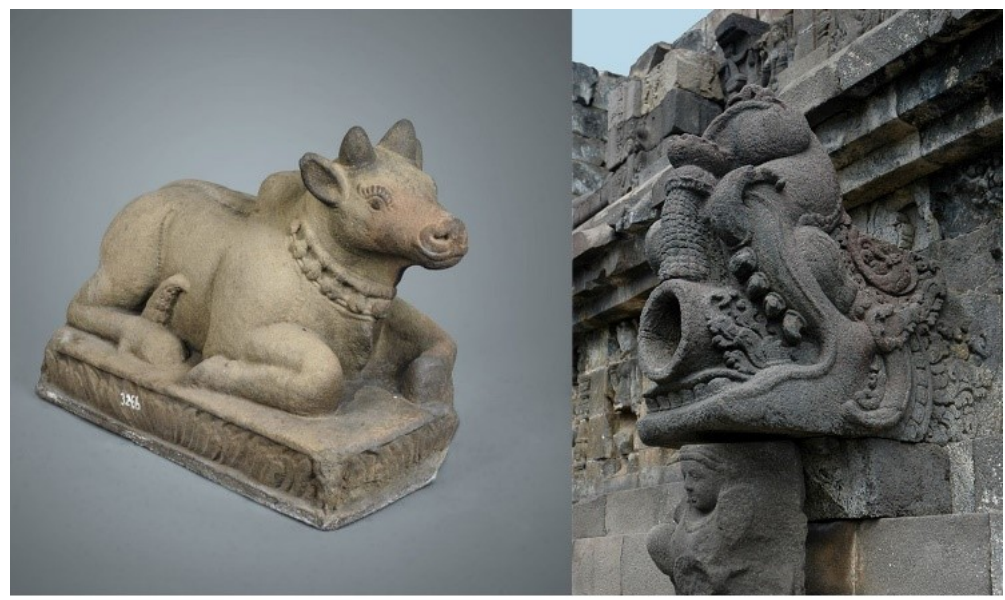

ARCA NANDI

ARCA JALADHAWANA

Gambar 3. Gambar Arca

Sumber gambar: https://geologi.co.id/2006/07/25/the-lost-of-the-indonesian-technology

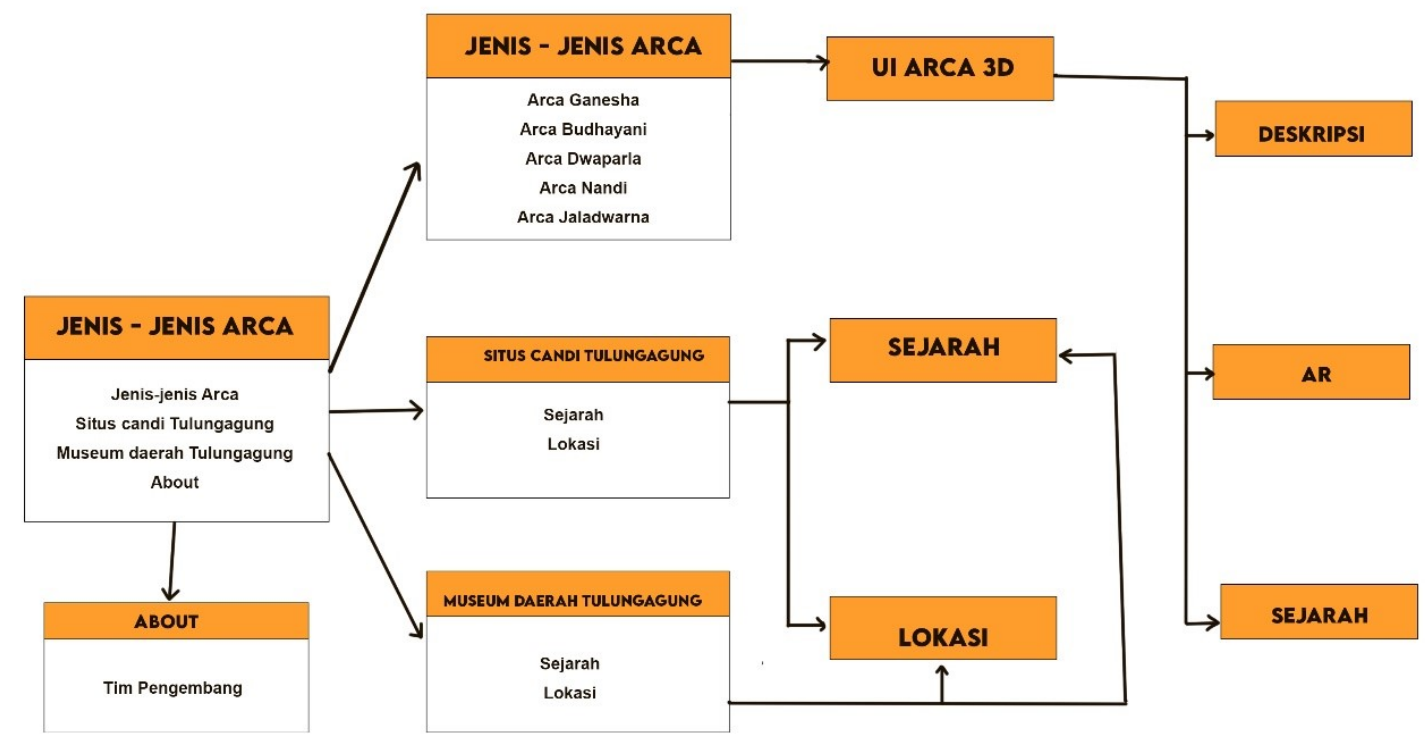

Gambar 4. Diagram alir 
dari sebuah objek sehingga dapat diidentifikasi dari warna, bahan maupun texture-nya. Tekstur adalah karakteristik untuk menganalisa permukaan berbagai jenis benda. Texturing merupakan kegiatan pembuatan tekstur sebuah permukaan benda 3D, Dalam tahap ini merupakan langkah pemberian warna pada model 3D. Pewarnaan dilakukan sesuai model referensi arca, dan dalam pembuatan pewarnaan menggunakan software substance painter

Exporting

Tahap akhir dari proses editing yang nantinya akan diolah ke dalam software 3D yang lain (Karthick, dkk,2015). Tujuan dari proses ini supaya model dapat di edit lebih lanjut, dengan software unity. Dalam export objek 3D dari zbrush ada beberapa hal yang perlu diperhatikan seperti seleksi objek yang ingin di export dan juga jenis ekstensi file yang akan digunakan $d i$ spark ar

\section{Layouting}

Merupakan tata letak objek 3D di Spark AR. Hal ini berguna supaya objek dapat ditampilkan sesuai dengan konsep atau rancangan pada arca 3D. dalam layouting hal yang perlu diperhatikan jarak objek ke kamera serta tata letak pencahayaan.

\section{Scripting}

Scripting adalah proses membuat logika program aplikasi (Barnawa, Sudana, \& Wibawa, 2019).Di Tahap ini semua elemen ditata dan disusun sesuai dengan interface model 3D arca Di Tahap ini setelah semua tampilan visual tertata maka langkah selanjutnya adalah membuat aplikasi berjalan sesuai mekanisme .Tahap ini dibagi menjadi 3 bagian besar yaitu screen pan, screen rotate, dan screen pich

\section{Tahap Detail Modeling Arca}

Proses pemodelan 3D memerlukan perancangan yang dibagi beberapa tahapan untuk pembentukannya (Nugroho \& Pramono, 2017). Referensi ini didapatkan dari sumber yang ada pada internet serta observasi di lapangan. Begitu referensi didapatkan selanjutnya penulis memasukan memasukan ke software pengolah 3D model yaitu zbrush dan blender. Pada aplikasi zbrush penulis membuat base mesh dari yang sudah disediakan oleh software zbrush. Dari basemesh tersebut selanjutnya akan akan di brush atau sculpting sehingga membentuk arca yang diinginkan.
Proses ini memakan waktu 3 jam sampai 1 hari untuk membuat 1 arca. Ketika 3D model sudah terlihat detail selanjutnya penulis membuat warna atau tekstur pada model tersebut,dengan cara memasukan 3D model ke file obj yang selanjutnya di import ke software substance painter. Dalam substance painter penulis memilih material batu atau yang lainya yang cocok untuk arca tersebut. Ketika pewarnaan selesai maka selanjutnya penulis memasukan tekstur ke software blender, kemudian masuk pada tahap pengurangan vertex atau polygon yang disebut remesh. Tahap tersebut berguna untuk meringankan model 3D sehingga dapat dimasukan ke software Spark AR.

\section{Tahap Pas ca Produksi}

Proses akhir dalam tahapan ini adalah pasca produksi. Kegiatan tersebut dapat berupa editing, komposisi, mixing dan creative engineering (Abidin, 2009).

\section{Testing dan Debugging}

Tahap produksi sudah selesai maka tahap selanjutnya adalah menguji coba aplikasi yang telah dibuat. Pada tahap ini sangat disarankan untuk bisa sedetail mungkin dalam memperhatikan berbagai bagian, terutama jika ditemukan adanya bug ataupun error yang akan dilanjutkan pada tahap debugging.

Debugging merupakan metode yang digunakan oleh programmer untuk menemukan dan menyelesaikan error pada program atau aplikasi komputer agar dapat bekerja sesuai dengan yang diharapkan (Aprilinda, 2012). Proses ini membutuhkan ketelitian dan pemahaman tentang software Spark AR yang digunakan, karena pesan error yang muncul menandakan bahwa aplikasi tidak dapat dijalankan. Kesalahan tersebut dapat disebabkan oleh beberapa bagian seperti salah ketik, bagian tidak disertakan atau bagian sisa. Hal-hal yang disebabkan. Selama pembuatan skrip, dan lainnya.

\section{Tahap Uji Coba Aplikasi}

Pengujian aplikasi dilakukan di dalam ruang pada hari Jumat, 22 Januari 2021 dengan beberapa merek smartphone. Dari hasil uji coba aplikasi dengan beberapa merek dan spesifikasi smartphone, didapatkanlah hasil sebagai berikut. 
Tabel 1. Hasil Uji Coba

\begin{tabular}{cccc}
\hline Merk HP & Spesifikasi HP & Keterangan \\
\hline 1. & Vivo y93 & Android 8.1 (oreo,Ram & Aplikasi berjalan lancar \\
& & $3 \mathrm{gb}$ & Kendala pada fokus kamera yang mengakibatkan susahnya \\
2. & Redmi note & Android 10, Ram 4gb & Filter berjalian lancar \\
9 & Realme 6 & Android 10, Ram 4gb & Tidak ada kendala sama sekali \\
3. & & Filter berjalan dengan lancar \\
& & & Tidak ada kendala apapun \\
\hline
\end{tabular}

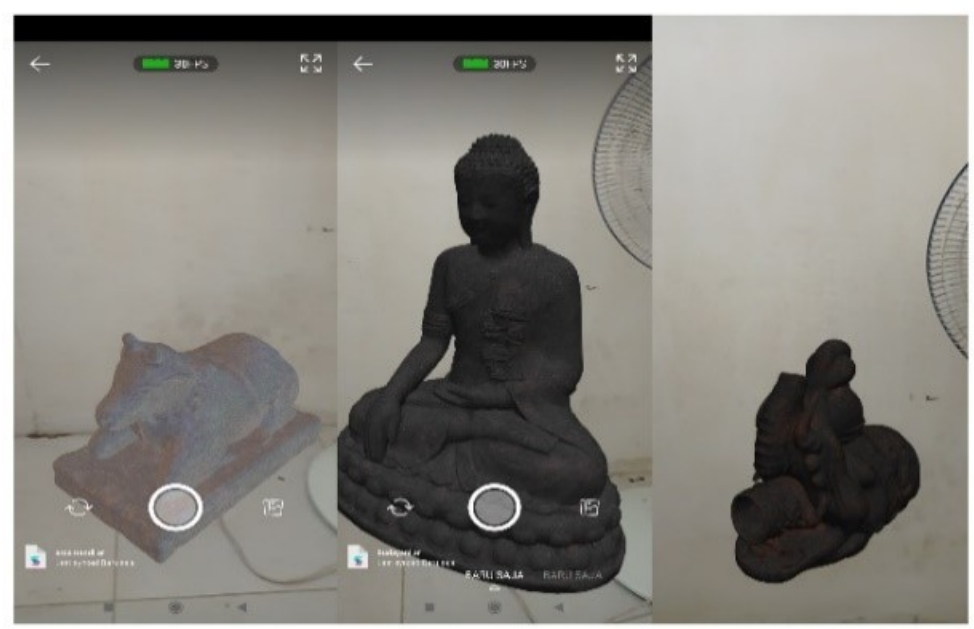

Gambar 5. Uji Coba aplikasi AR

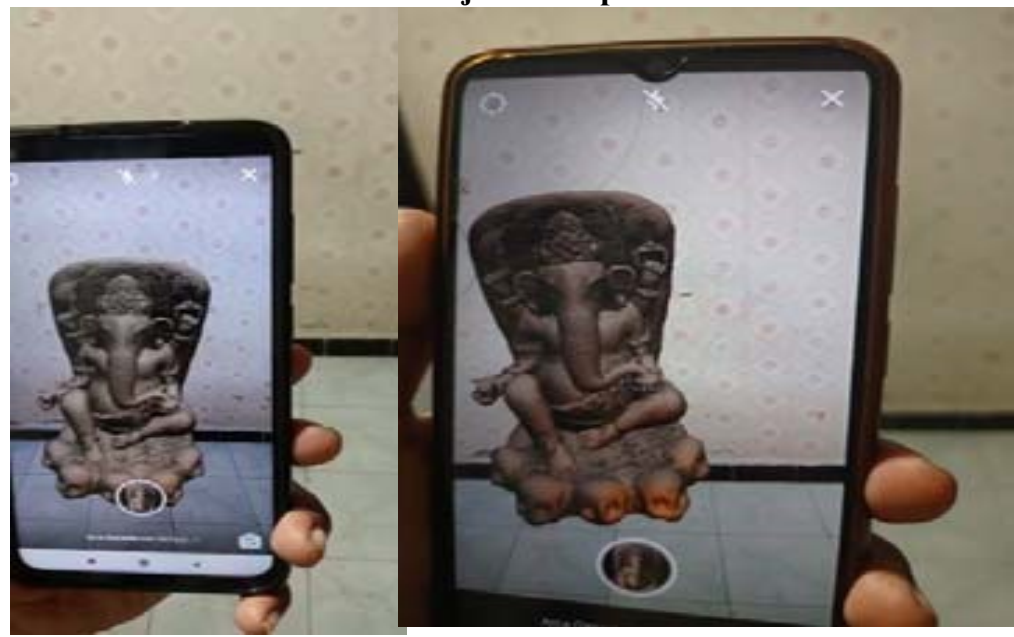

Gambar 6. Uji Coba aplikasi AR

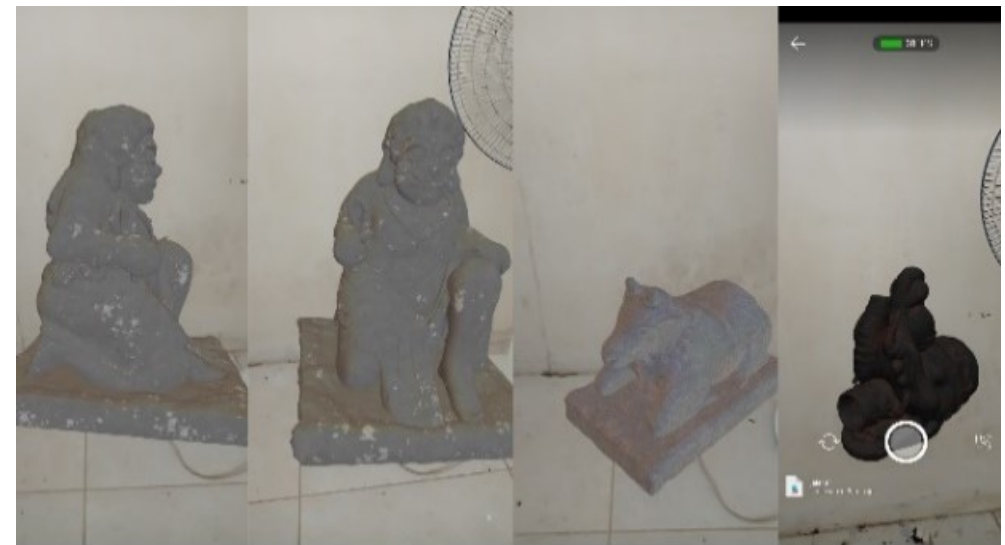

Gambar 7. Uji Coba aplikasi AR Dwaparla, Nandi dan Jaladwara 


\section{Hasil Survei Penilaian Pengguna}

Pengujian filter dilakukan dengan survei yang melibatkan kurang lebih sekitar 60 kuesioner. Poin pada survei sebagaimana dijelaskan Scheuren, (2004) dibuat supaya penulis dapat menerima umpan balik dari para pengguna supaya kedepannya dapat berkembang menjadi lebih baik. Berdasarkan hasil survei mengenai kesesuaian dan akurasi model dan visual diperoleh data sebagaimana pada Gambar 8.

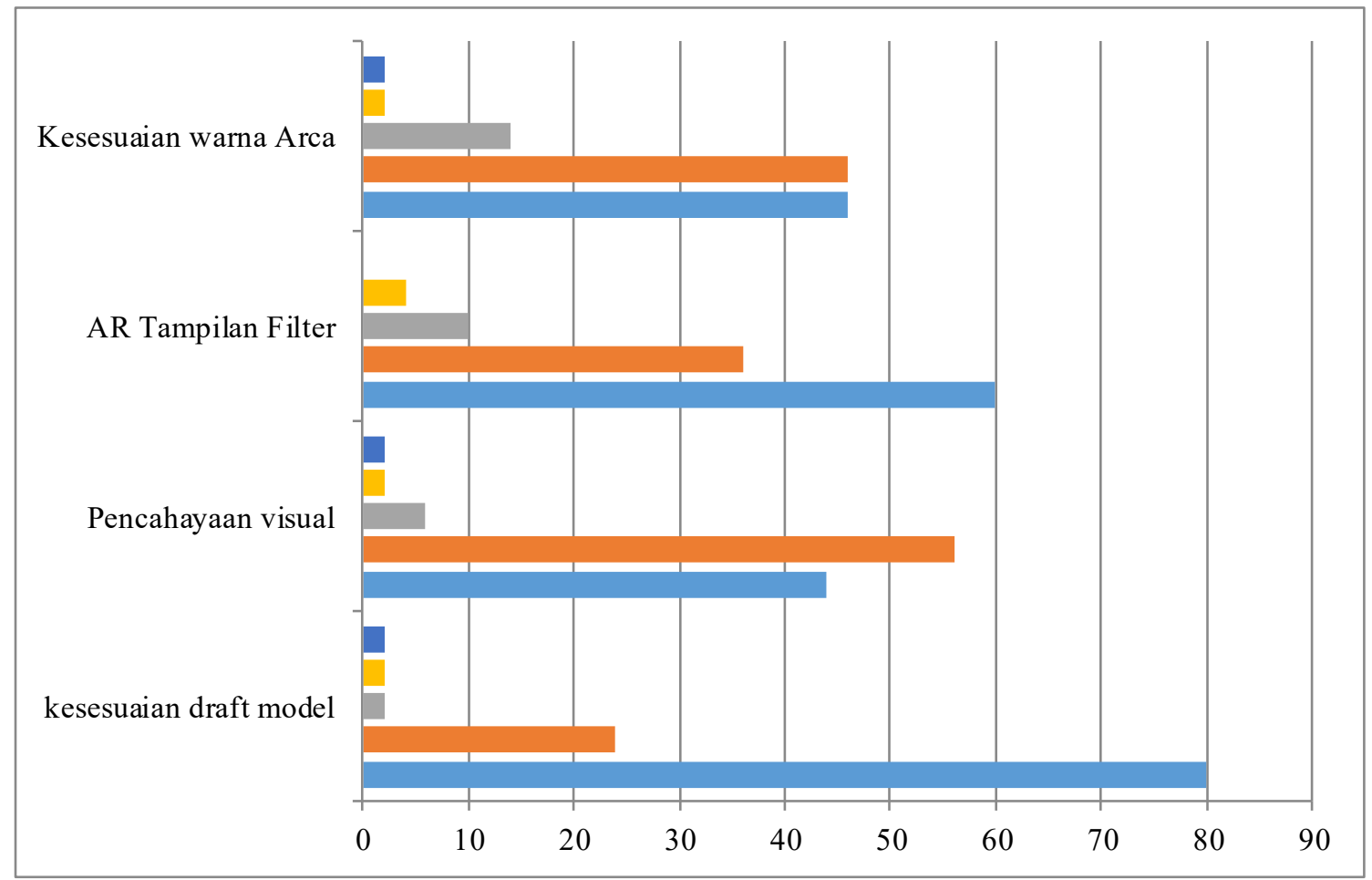

Gambar 8. Kesesuaian dan akurasi model Visual AR

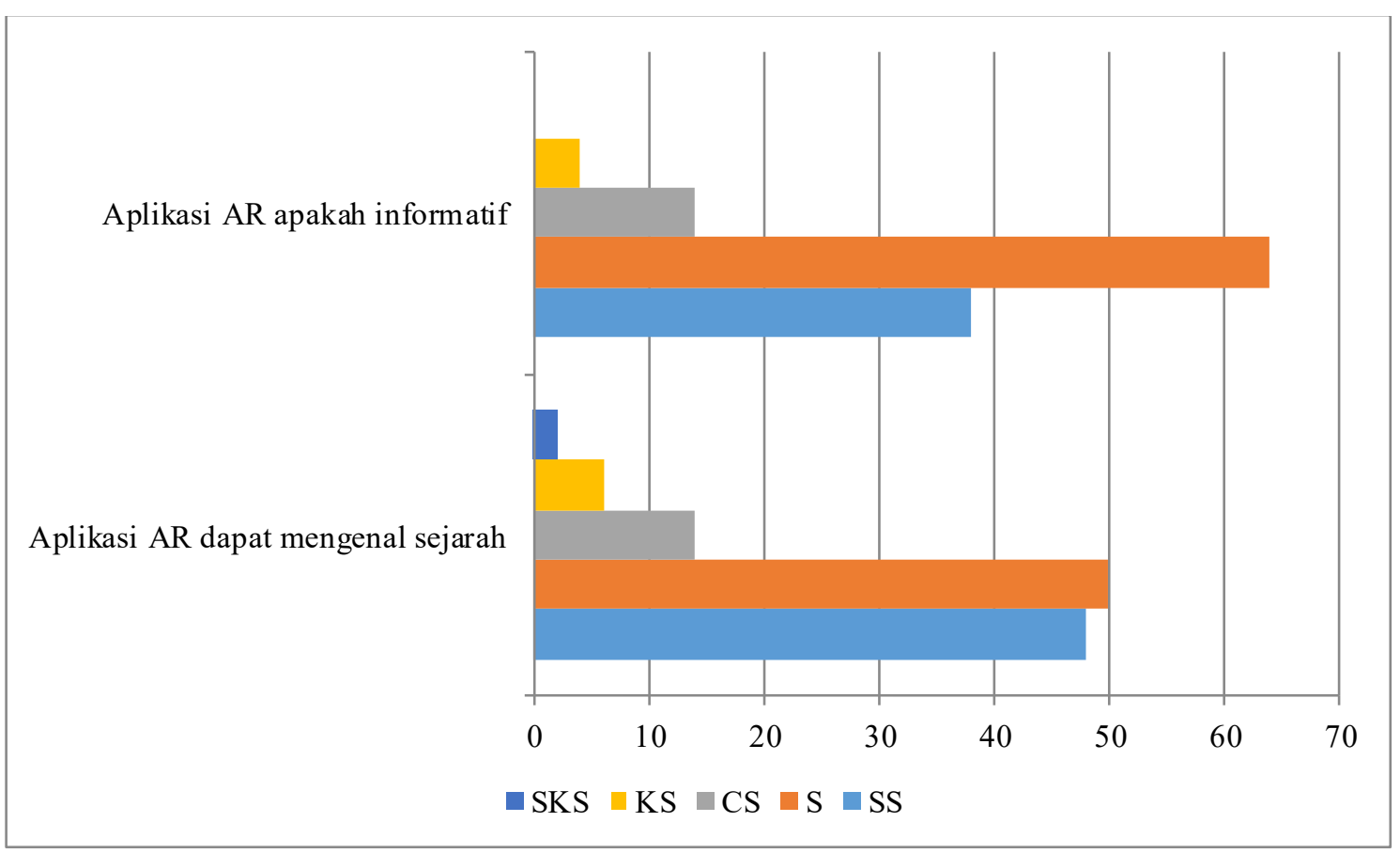

Gambar 9. Fungsi aplikasi AR berdasarkan pengguna 
Dari hasil survei menunjuk-kan kesesuaian warna arca, Ar tampilan Filter, Pencahayaan visual dan Kesesuaian draf model didapatkan hasil diagram gambar diatas menunjukan kesesuaian dan akurasi model dan visual ar $89 \%$. Dapat disimpulkan bahwa model 3D yang telah dibuat oleh penulis sudah sesuai dengan arca aslinya.

Dari hasil survei mengenai pertanyan aplikasi Ar apakah informatif dan Aplikasi AR dapat mengenal sejarah didapatkan dari hasil gambar diatas menunjukan aplikasi AR arca informatif dan dapat mengenalkan sejarah 167\%. Dari kesimpulan diagram diatas, informasi yang disampaikan penulis mengenai detail sejarah sudah informatif.

\section{PEMBAHASAN}

Penelitian ini untuk edukasi masyarakat mengenai arca yang ada di daerah Kabupaten Tulungagung. merupakan wadah bagi para peneliti di lingkungan Universitas untuk menerapkan atau transfer teknologi hasil penelitian yang berupa ilmu pengetahuan dan teknologi (IPTEK) guna menyelesaikan permasalahan yang ada di masyarakat. Permasalahan yang berkembang di masyarakat khususnya daerah kabupaten Tulungagung saat ini adalah kurang minatnya masyarakat mengenal situs sejarah terutama arca. Sehingga dibutuhkan upaya untuk membuka wawasan sejarah tentang situs di Tulungagung, salah satunya dengan pembuatan Augmented reality.

Berdasarkan analisis permasalahan tersebut, penelitian ini bertujuan untuk menambah wawasan bagi masyarakat serta mengembangkan teknologi augmented reality, dengan memanfaatkan aplikasi digital dan dalam penelitian ini banyak permasalahan atau kendala dalam mencari sumber aslinya karena kendala di masa pandemic saat ini penulis tidak dapat pergi ke museum daerah Tulungagung serta banyak sebagian arca yang ditemukan dalam keadaan rusak. Kurangnya informasi untuk mengetahui tentang situs sejarah yang berada di kabupaten Tulungagung. Dalam penelitian yang berkaitan tentang Augmented reality, model perancangan yang digunakan seperti yang digambarkan pada Gambar 1. Pengambilan data yang digunakan meliputi instrumen ahli media, ahli materi dan angket untuk selanjutnya akan diberlakukan analisa kebutuhan dan tujuan.

Berdasarkan hasil analisis selanjutnya akan melakukan tahapan konsep meliputi produksi, pra-produksi dan pasca-produksi. Konsep media meliputi konsep layout interface juga mengenai konsep model arca 3D. Pramono, (2013) menyatakan bahwa sangat berbeda jauh dengan hasil penelitian yang dilakukan oleh penulis. Pada tahap yang dilakukan peneliti terdahulu menggunakan konsep yang berbeda dan dalam skenario media menggambarkan konsep linear scripting yang mendefinisikan tipe-tipe rumah adat yang seharusnya menjadi penanda. Setelah fase desain selesai, lanjutkan ke fase implementasi, yang meliputi desain antarmuka, desain penanda, model perumahan tradisional, dan skenario alat campuran. Pada tahap ini perancangan aplikasi ar dikompilasi dan langkah selanjutnya adalah tahap rendering ar untuk menyusun kamera, desain interface, desain marker, model dan skenario rumah adat, salah satu tema rumah adat adalah satu.

Ada juga survei yang meliputi wilayah indonesia, survei area rumah adat indonesia, namun survei ini memiliki beberapa perbandingan penggunaan survei ini dengan dapat menganalisa survei spesifik yang ada khususnya tema yang berbeda. Memungkinkan untuk memproses beberapa penanda secara bersamaan. aplikasi yang berbeda dengan penulis, di dalam aplikasi peneliti terdahulu, dapat menampilkan desain antarmuka aplikasi ar yang belum pernah terlihat pada penelitian sebelumnya. Cakupan survei yang dilakukan ini juga sangat luas, termasuk 15 gaya rumah tradisional indonesia. Pola penandaan juga tidak sama dengan penulis karena berbeda aplikasi yang digunakan.

Pada penelitian terdahulu menggunakan spidol multicolor lebih baik dibandingkan penelitian yang penulis buat serta menggunakan spidol hitam putih. Keberadaan media sosial sangat mempengaruhi. Serta perkembangan teknologi yang pesat, tidak dapat dipungkiri penyebaran informasi akan lebih cepat kita ketahui (Dahlman dkk, 1987). Perkembangan teknologi negara-negara industri baru untuk menarik beberapa pelajaran penting bagi perusahaan dan pemerintah di negara berkembang lainnya. ada banyak social media yang dapat digunakan sebagai sarana penyebaran informasi. 
Tidak hanya penyebaran informasi, pengetahuan akan sejarah juga dapat dilakukan menggunakan social media. Seluruh kalangan masyarakat sudah mengenal social media dan sangat mahir dalam pengaplikasiannya, tak terkecuali di kabupaten Tulungagung. Serta menurut penelitian yang dengan (Pramono, 2021). The game application is one of the leading choices of cellular media users, bahwa sebagian besar anak-anak sangat gemar bermain smartphone dan berdasarkan kajian analisis mengenai augmented reality yang mengangkat tema sejarah antara penelitian penulis dan penelitian yang telah dilakukan oleh Pramono, (2017). dapat diambil kesimpulan bahwa terdapat perbedaan yang cukup banyak terutama pada bagian penulisan. Tingkat keakuratan informasi lebih akurat dalam penelitian yang dilakukan Pramono, (2017), namun secara kualitas karya visual cenderung kurang sesuai dengan aslinya sedangkan milik penulis tingkat akurasi secara visual sangat kuat dibandingkan penelitian sebelumnya.

Selain mendukung dalam pendidikan, desain arca 3D yang merupakan bentuk inovasi dalam pengenalan situs sejarah.dan juga menurut (Hein, 2006), museum merupakan sehingga akan mendukung dari segi pemasaran museum wajakensis bahkan Kabupaten Tulungagung sendiri. Hal tersebut sependapat dengan pendapat dari Cravens (2001) dimana menjelaskan bahwa diferensiasi dalam pemasaran akan menghasilkan promosi yang unggul karena berbeda dengan pesaingnya. jenis media online, pengguna media sosial dapat dengan mudah berpartisipasi, berbagi, dan membuat konten, termasuk blog, jejaring sosial, (Cahyono, 2016).

Dengan perancangan filter di media sosial nantinya, arca yang terdapat di museum wajakensis akan lebih dikenal masyarakat luas dengan seiring banyak digunakannya filter tersebut dalam sosial media. Hal tersebut juga dapat meningkatkan popularitas Kabupaten Tulungagung dengan adanya inovasi tersebut. Menurut Haryani, \& Triyono, (2017). Metode AR terdapat 2 metode yang dikembangkan saat ini yaitu menggunakan metode berbasis marker dan tidak menggunakan marker. Dengan membuat AR, pengguna filter tidak perlu lagi mencetak kertas tanda untuk menampilkan elemen digital. Tanda yang dikenali ada dalam bentuk lokasi perangkat, arah, atau lokasi.

Deteksi fitur target dan pelacakan target berdasarkan pose kamera mengadopsi metode yang digunakan dalam pelacakan tanpa tanda. Sift (scale invariant feature transformation) dan surf (accelerated robust feature) adalah dua metode terbaru untuk pelacakan bebas label. Kedua metode ini tidak hanya mendeteksi tempat menarik (poi), tetapi juga mengusulkan metode untuk membuat deskriptor. Sebagian tidak berubah. Deskriptor ini dapat digunakan untuk mengidentifikasi poi secara unik dan cocokkan, bahkan dalam kondisi yang berubah: skala, rotasi, pencahayaan, sudut pandang, atau kebisingan. Kekekalan ini merupakan standar penting yang sering dihadapi sistem seluler kondisi lingkungan yang tidak stabil dan tidak berulang.

Penulis memiliki inovasi dalam menambah wawasan sejarah bagi masyarakat luas baik masyarakat kabupaten Tulungagung sendiri maupun luar kabupaten Tulungagung. Desain arca 3D sebagai AR (Augmented reality) di inovasikan sebagai media pengenalan arca daerah kabupaten Tulungagung. Desain arca 3D nantinya digunakan dalam bentuk filter di berbagai media social. Produk perancangan filter 3D Arca yang dapat diakses melalui mobile ini dapat digunakan oleh pengajar maupun masyarakat untuk memberikan edukasi dalam pengetahuan dan wawasan mengenal situs sejarah (Hutchinson, 2017). Diharapkan penulisan tugas akhir ini dapat dimanfaatkan dengan sebaik-baiknya dan sesuai dengan penggunaan yang seharusnya.dan penulis hanya merancang untuk situs sejarah dengan terbatas. Kedepannya penulis berharap untuk perancangan media dalam tema mengenal situs sejarah arca dapat dikembangkan lebih lanjut, seperti animasi 3D yang dapat bercerita lebih lengkap dan media lainnya sehingga dapat membuat masyarakat tertarik untuk mengenal Arca.

Filter augmented reality 3D bisa membagikan inovasi dalam pembelajaran untuk publik khususnya sebagai daya tarik wisata museum daerah (Subhiksu dkk, 2018). Kedepannya penulis berharap untuk dapat menjalankan penelitian selanjutnya untuk mengembangkan AR ke tingkat selanjutnya seperti XR (Silverstone, \& Ravindran, 1999). 


\section{SIMPULAN}

Keberadaan suatu media sangat berarti buat mendukung proses belajar .Media buku yang sudah biasa digunakan dianggap telah sangat biasa serta membosankan. Bisa dibilang media merupakan aspek utama keberhasilan dalam penyampaian suatu modul. Untuk itu media sepatutnya bisa untuk buat digunakan supaya audience juga pula semangat dalam belajar. Di dalam tema memahami situs sejarah inilah yang jadi daya tarik buat memperoleh sasaran audience. Bisa membagikan inovasi dalam pembelajaran untuk publik spesialnya dalam tema memahami sejarah inilah buat memperoleh sasaran audience.

Tujuan utama dari media ini bukanlah untuk mengambil alih media konvensional yang telah terdapat tetapi bertujuan untuk menarik atensi serta memancing rasa ingin tahu dari sasaran audience untuk belajar memahami situs daerah. Aksess filter yang gampang serta instan pula akan mempermudah pemakaian media ini. berdasarkan hasil survei menunjukan banyak memberi respon positif pada karya Augmented reality. Selain itu VR namun dengan tingkat kedetailan yang lebih tinggi lagi. semoga penulisan artikel jurnal ini dapat dimanfaatkan sebaik- baiknya.

\section{DAFTAR RUJUKAN}

Agrarian, R. P., Suprayogi, A., \& Yuwono, B. D. (2015). Pembuatan aplikasi mobile gis berbasis android untuk informasi pariwisata di kabupaten gunungkidul. Jurnal Geodesi Undip, 4(2), 241-247.

Angel, E. (1996). Interactive Computer Graphics: A top-down approach with OpenGL. AddisonWesley Longman Publishing Co., Inc..

Aprilinda, Y. (2012). Perancangan Aplikasi Penjualan Pupuk Dengan Menggunakan Microsoft Visual Foxpro 8.0 Pada Koperasi Mitra Sehati Kota AgungTanggamus. Explore: Jurnal Sistem informasi dan telematika (Telekomunikasi, Multimedia dan Informatika), 3(1).

Barnawa, I. B. B., Sudana, A. A. K. O., \& Wibawa, K. S. MepandesVR, Aplikasi Virtual Reality Media Pembelajaran Animasi 3D Prosesi Upacara Mepandes di Bali Berbasis Android.

Cahyono, A. S. (2016). Pengaruh media sosial terhadap perubahan sosial masyarakat di Indonesia. Jurnal Publiciana, 9(1), 140-157.

Dahlman, C. J., Ross-Larson, B., \& Westphal, L. E. (1987). Managing technological development: lessons from the newly industrializing countries. World development, 15(6), 759775.

Eriza, M. H., Pramono, A., \& Novica, D. R. (2021). Augmented Reality Character Topeng Malang Dewi as an Effort to Improve the Quality of Student LearningMedia. KnE Social Sciences,258-

265.https://doi.org/10.18502/kss.v5i3.8548

Haryani, P., \& Triyono, J. (2017). Augmented reality (AR) Sebagai Teknologi Interaktif Dalam Pengenalan Benda Cagar Budaya Kepada Masyarakat. Simetris: Jurnal Teknik Mesin, Elektro Dan Ilmu Komputer, 8(2), 807-812.

Hein, G. E. (2006). Museum education. A companion to museum studies, 340-352.

Heru, S. (2015). Strategi pemasaran pesantren studi kasus pondok pesantren Darul Huda Mayak (Doctoral dissertation, STAIN Ponorogo).

Hidayat, I. K., Rini, D. R., Novica, D. R., Azhar, K., \& Daud, M. (2019). Implementing Augmented reality and gamification intourism. International Journal of Technology Management, 1(1), 37-42.

Hidayat, W. N., Sutikno, T. A., Patmanthara, P., Kartikasari, C. D. I., \& Firdaus, A. F. (2019). Peningkatan Keterampilan Pembuatan Media Pembelajaran Berbasis Augmented Reality Untuk GuruSmk. Jurnal Graha Pengabdian, l(2), 93-103.

Hutchinson, J. (2017). Audience Participation in Media Organisations. The registered company is Springer International Publishing $A G, 11(3), 316-328$.

Karthick, M., Shatish, M., Swathika, S., SubhaShree, S., Vasudevan, S. K., \& Kiran, V. K. (2015). Exporting Files into Cloud Using Gestures in Hand Held Devices-an Intelligent Attempt. Procedia Computer Science, 50, 258-263.

Kasih, T. Z. (2014) Aplikasi Augmented reality sebagai media pembelajaran manasik haji berbasis android device (Doctoral dissertation, Universitas Muhammadiyah Surakarta).

Novica, D. R., Hidayat, I. K., \& Sutrisno, A. A. (2020). Aesthetic of Cuteness Dimensions in Malang CityMascot. KnE Social Sciences, 162-171.

Novica, D. R., Hidayat, I. K., \& Yahya, A. R. I. I. (2020, March). Designing Urban Toys to Support Local Traditional ArtsInn a2nd International Conference on Arts and Design Education (ICADE 2019)(pp. 46-50). Atlantis Press.

Nugroho, A., \& Pramono, B. A. (2017). Aplikasi mobile Augmented Reality berbasis Vuforia dan Unity pada pengenalan objek 3D dengan studi kasus gedung $\mathrm{m}$ Universitas Semarang. Jurnal Transformatika, 14(2), 86-91. 
Pramono, A. (2017). Media Pendukung Pembelajaran Rumah Adat Indonesia Menggunakan Augmented Reality. Jurnal Eltek, 11(1), 122132.

Pramono, A. (2021). Character Thematic Education Game" AK@ R" of Society Themes for Children with Malang-Indonesian Visualize. International Journal of Instruction, 14(2), 179-196.

Pramono, A., Rahayuningtyas, W., Puspasari, B. D., \& Ismail, A. I. H. (2020). Development Educational Material Topeng Malang with the Augmented Reality for SupportingCharacter. KnE Social Sciences, 631639.https://doi.org/10.18502/kss.v4i12.7637

Rahmawati, W. P. (2017). Arti Simbolis Arca Buddha Maha-Aksobhya (Prasasti 1289) Sebagai Media Pencegahan Perpecahan Kerajaan Singhasari. Avatara 5(3).https://jurnalmahas is wa.unesa.ac.id/inde x.php/avatara/article/view/20294
Sari, C. F. A., \& Yulianto, L. (2013, March). Perancangan sistem informasi absensi menggunakan finger print di badan perencanaan pembangunan daerah dan penanaman modal kabupaten pacitan. In Seruni-Seminar Riset Unggulan Nasional Inoformatika dan Komputer (Vol. 2, No. 1).

Scheuren, F. (2004, June). What is a Survei?. Alexandria: American Statistical Association.

Silverstone, P. H., \& Ravindran, A. (1999). Oncedaily venlafaxine extended release (XR) compared with fluoxetine in outpatients with depression and anxiety. The Journal of clinical psychiatry, 60(1), 0-0.

Subhiksu, I. B. K., \& Utama, G. B. R. (2018). Daya Tarik Wisata Museum Sejarah dan Perkembangannyadi Ubud Bali. Deepublish.

Untari, R. R. (2018) Peranan Museum Wajakensis sebagai sumber belajar di Kabupaten Tulungagung (Doctoral dissertation, Universitas Negeri Malang). $\underline{\text { http://repository.um.ac.id/55330/ }}$ 